\title{
Rheological behavior of acrylic paint blends based on polyaniline
}

\author{
Alex da Silva Sirqueira ${ }^{1 *}$, Dermeval Teodoro Júnior ${ }^{1}$, Marcio da Silva Coutinho", \\ Artur Soares da Silva Neto ${ }^{1}$, Adriana dos Anjos Silva ${ }^{1}$ and Bluma Guenther Soares ${ }^{2}$
}

\author{
${ }^{1}$ Laboratório de Engenharia de Polímeros e de Aplicações Industriais, Centro Universitário Estadual \\ da Zona Oeste - UEZO, Rio de Janeiro, RJ, Brazil \\ ${ }^{2}$ Programa de Engenharia Metalúrgica e de Materiais - PEMM, Instituto Alberto Luiz Coimbra de \\ Pós-Graduação e Pesquisa de Engenharia - COPPE, Universidade Federal do Rio de Janeiro - UFRJ, \\ Rio de Janeiro, RJ, Brazil
}

*alexsirqueira@uezo.rj.gov.br

\begin{abstract}
The rheological properties of acrylic paints and polyaniline (PAni) blends, with different contents of PAni doped by dodecyl benzene sulphonic acid (DBSA) and, dispersed by mechanical stirrer and ultrasonic, were investigated by controlled shear rate testing ramps. The results showed that the commercial acrylic paint had tended to deliver the required stability on the blends, in order to avoid sedimentation process. All samples exhibited non-Newtonian flow behavior (shear thinning), increasing PAni content the flow behavior index ( $n$ ) decreased (0.41 to 0.11 ) and power law model were used to fitted the experimental curves. The results showed that the addition of PAni-DBSA affects the viscoelastic behavior of the mixtures due to the interactions between the components in the mixture. The best properties were obtained for samples $90 / 10 \mathrm{wt} \%$ dispersed by ultrasonic, indicating the feasibility of the usage as a conducting paint.
\end{abstract}

Keywords: polyaniline, acrylic paint, thixotropy.

\section{Introduction}

Inherently Conducting Polymers are considered to be organic materials which exhibit electrical, magnetic and optical properties very similar to metals and semiconductor materials, these kinds of polymers, have conjugated double bonds of polymer chains, which allow an electron flow under specific conditions. The oxidation/reduction processes from polymeric chains, are carried out by charge transfer agents, changing the insulator nature from polymers to a conducting or semi-conducting nature, due to an increase of both electrons mobility and conductivity ${ }^{[1-3]}$.

The chemical doping is a reversible process which occurs by protonation in aqueous acid solution, with no changes on the number of electrons associated with the polymer chains, basically, consists of protons addition to the polymer chains of a doping agent, leading to the shift of electrons from $\pi$ system $^{[4]}$. Studies have shown that certain conducting polymers such as Polyaniline and Polypyrrole have been found to offer corrosion protection of iron, steel and aluminum, attributed to its high stability in the air, adhesion and redox properties with the substrate ${ }^{[5-9]}$. Amongst the class of conducting polymers, Polyaniline (PAni) is unique due to its easy synthesis, low cost, good thermal stability, and reversible doping/dedoping process to control the conductivity ${ }^{[10,11]}$. When reaction occurs in acidic environment (low $\mathrm{pH}$ condition), leads the head-to-tail coupling of aniline monomers in the para position and green form as a protonated emeraldine, which can be dedoped by oxidizing agent to produce the blue, emeraldine base form of the semi-conducting polymer ${ }^{[12-14]}$.
On the other hand, it is well known the insoluble and infusible nature of ICPs has kept them away from the formation of solutions/melt. The mechanical properties of conducting PAni have been investigated in the scientific literature only with respect to its blends, PAni usually acted as particulated conducting filler in a suitable matrix that provided the required mechanical properties. In order to overcome the intractability of ICPs and to bring them into the solution/melt, some techniques such as: introduction of bulky side groups or dopant ions into the polymeric chain or use of polymeric or surfactant stabilizers optimize the formation of ICP solutions ${ }^{[15-17]}$

Blends of conducting polymers with conventional polymers have been extensively studied ${ }^{[18-21]}$. Their mixture with conventional polymers consists of a good strategy from the technological point of view ${ }^{[22-24]}$.

As rheology is considered to be an efficient tool for exploring structural properties and molecular interactions of different materials, it will be applied, as a technique for blends macroscopic characterization, on the other hand, it will provide an easily accessible way to correlate the microstructure of a system with its particular rheological responses on PAni-based systems ${ }^{[25-27]}$.

The main of this article will compare the rheological behavior of Acrylic Paints/PAni blends and evaluate the influence of sample preparation methodology on the viscoelastic properties. It known the use of PAni, or another conducting polymer to improve the corrosion protection, but they're very little paper showing e rheological behavior after the addition of conducting polymer. Rheology will provide 
useful information for prediction of blends behavior during development of conducting paints, due to it determines the performance of the paint during the whole handling cycle, from storage to application and drying ${ }^{[25,28-30]}$.

\section{Materials and Methods}

\subsection{Materials}

Commercial acrylic paint was kindly supplied by Akzo Noble (Brazil). The characteristic of the commercial paint is given in Table 1 .

The PAni.DBSA was obtained by mixing aniline/DBSA in the molar ratio $1: 1$ in $75 \mathrm{ml}$ water/methanol mixture (3:1), under vigorous stirring for 7 minutes. Then $20 \mathrm{ml}$ of ammonium persulfate $(0.1 \mathrm{~mol})$ as oxidizing agents was slowly added in the solution. The polymerization reaction was carried out at $0{ }^{\circ} \mathrm{C}$ under vigorous stirring. After 6 hours, the reaction medium was poured into methanol, filtered, washed several times with methanol, and dried under reduced pressure for $72 \mathrm{~h}^{[31]}$.

Acrylic paint with doped PAni concentration rises from $5 \%$ to $10 \% \mathrm{w} / \mathrm{w}$ were obtained by dispersing using a mechanical stirrer and ultrasonic at room temperature. Mechanical dispersion was carried out with a constant stirring speed of 300 RPM for 10 minutes. Ultrasonic dispersion was carried out in ultrasonic device, the sonotrode used to have tip diameter $3 \mathrm{~mm}$ and made of titanium. The dispersion was carried out in the following conditions: $100 \mathrm{~W}$ power, at constant frequency of $30 \mathrm{kHz}$, and constant amplitude of $50 \%$ over five minutes.

\subsection{Rheological measurements}

The rheological characterization was carried out using a shear rate-controlled rotational rheometer (Haake Rotovisco RV20/CV20N) (Couette flow) fitted with a Mooney-Ewart coaxial cylinder sensor (inner cylinder diameter $28.93 \mathrm{~mm}$, outer cylinder diameter $30.0 \mathrm{~mm}$, length $24.0 \mathrm{~mm}$, and sample volume $1.8 \mathrm{~cm}^{3}$ ). The temperature was controlled with an accuracy of $25 \pm 0.1^{\circ} \mathrm{C}$ by circulating water in the jacket of the outer cylinder arrangement.

\subsubsection{Viscosity measurements}

The Power-law model was used to study the flow behavior of the formulations:

$$
\begin{aligned}
& \mu=k(d \gamma / d t)^{n-1} \\
& \tau=k \dot{\gamma}^{n} \\
& \ln \mu=\ln k+(n-1) \ln \dot{\gamma}
\end{aligned}
$$

Where: $\mu$ is the viscosity, $\mathrm{t}$ is the time, $\tau$ is the shear stress; $\mathrm{k}$ a constant; $\dot{\gamma}$ the shear rate; and $n$ the non-Newtonian power index.

The samples were investigated by controlling shear rate testing ramps from 0 to $500 \mathrm{~s}^{-1}$.

\subsubsection{Creep and recovery test}

In creep and recovery test, generally, elastic deformation may be resembled by a spring model and viscous flow by a dashpot model. The quantity of springs and dashpots and the way in the sample body, which they are connected, can be used to represent different kinds of viscoelastic materials ${ }^{[31]}$. Creep and recovery tests were carried out under the shear stress of $5 \mathrm{~Pa}$ at $25^{\circ} \mathrm{C}$, the variation of the strain in response to the applied stress was measured of a period of 3 minutes, afterwards, the stress was then removed, and changes in strain were registered through a further period of 3 minutes, in order to observe structure recovery, using the evaluation tool from Software Rheowin3, was also possible to provide viscosity zero shear rate and relaxation time determination.

\section{Results and Discussions}

\subsection{Rheological behavior}

The viscosity is denominating the resistance of a fluid against any force tending to cause the flow. It is one of the most important properties in rheological studies for coating, paint and ink. To obtain a good application characterization, good paint has to be non-Newtonian liquid behavior, which are shear rate dependent. Rheological characterization of paint is to measure the relationship between shear stress and rate of shear strain variation harmonically with time ${ }^{[32]}$.

Figure 1 shows the viscosity variation as a function of shear rate, it is observed that all samples exhibited a typical rheological behavior of non-Newtonian fluid, the viscosity decreased rapidly with the increase of the shear

\begin{tabular}{|c|c|c|c|}
\hline Manufacturer & Commercial paint & Description & Product information \\
\hline \multirow{10}{*}{ Azko Noble Ltda } & \multirow{10}{*}{ Coralar acrilico } & \multirow{10}{*}{ Water based paint } & Color: white \\
\hline & & & Solid content: $56 \%$ \\
\hline & & & Viscosity: 90-100 UK \\
\hline & & & Volatiles: $53-56 \%$ \\
\hline & & & Titanium dioxide: $1-5 \%$ \\
\hline & & & Ethoxyl alcohol: $<0.1 \%$ \\
\hline & & & Ammonium: $0.1-1.0 \%$ \\
\hline & & & Aluminum silicate: $10-30 \%$ \\
\hline & & & Calcium carbonate: $15-40 \%$ \\
\hline & & & Application method: air spray, brush or roller \\
\hline
\end{tabular}
rate, this is called pseudoplastic behavior, and this behavior

Table 1. The characteristic of the commercial paint. 
is characteristic of the textural changes in the samples may be induced by the shear rate. For Newtonian fluids, $n=1$ and $\ln \mathrm{k}=\ln \mu$, but for a pseudoplastic fluid the index $n$ is associated to the viscoelastic parameter and take values smaller 1. The pseudoplastic behavior can be attributed to the polymer chain pulled apart to be arranged in straight chain when the polymer is in shear flows. At low strain region shows non-linear viscosity characterized weak (physical) gel forned by hydrogen bonding between the amine, imine and carboxyl groups. In this work two amounts of conducting polymer were added in the acrylic paint $5 \%$ and $10 \%$, by two different dispersion methodologies, mechanical mixer and ultrasonic. Analyzing the addition of PAni 5\% w/w, in the range of 50 to $100 \mathrm{~s}^{-1}$, it was not observed any difference in the curve between acrylic paint and the dispersion by mechanical mixer. But, when the ultrasonic methodology was used to disperse PAni, the viscosity curve showed high value. It can be an indication that the sample had better dispersion of PAni in acrylic paint, because the ultrasonic dispersion experiment generates high shear that breaks particle agglomerates in single dispersed particles. It is known, PAni has a high tendency to agglomerate ${ }^{[33]}$, been individual molecules cluster to form primary particles (organic metals), which then form primary aggregates. Primary aggregates cluster to form secondary particles ${ }^{[29]}$. The weak bonding of dipole force between polymer molecules in a physical gel can be easily broken by the external shear deformation, resulting in the delay of gelation process. Therefore, the increase of viscosity promoted by ultrasonic dispersion is an indication that the sample had better dispersion of PAni in acrylic paint, because the ultrasonic dispersion experiment

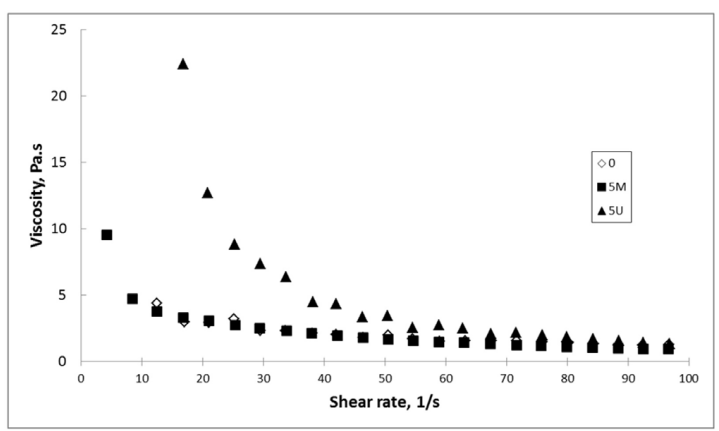

(a)

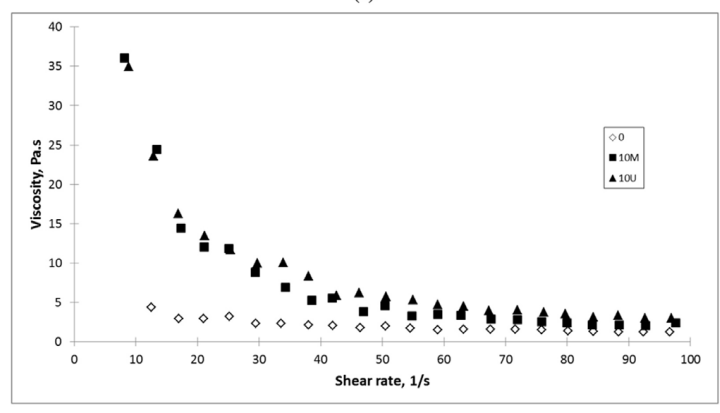

(b)

Figure 1. The dependency of Paint Viscosity in shear rate condition (a) for $5 \%$ PAni and (b) for $10 \% \mathrm{w} / \mathrm{w}$. generates high shear that breaks particle agglomerates in single dispersed particles.

When increase the amount of $5 \%$ to $10 \% \mathrm{w} / \mathrm{w}$ of PAni in acrylic paint, any difference in curve were observed by dispersion methodology. In this condition, $10 \% \mathrm{w} / \mathrm{w}$ of PAni, probably the amount of polymer will determine the curve behavior of viscosity.

When trying to add a filler or an insoluble polymer into the paint formulations some practical aspect appears like precipitate of this additive. An example that rheological characterizations for paint applications is the forecast of settling property. High viscosity in low shear zone is a reflection of good anti-settling property and stable filler suspension in storage condition. The PAni add in Acrylic paint, improve the anti-settling property, but it is difficult specify the mechanism of anti-settling in a commercial acrylic paint due the many variables (morphology, molecular weight, number and type of additives, etc.). However, it is may be reasonably assumed that the anti-settling effect is caused by the formation of hydrogen bonds between PAni and Acrylic resin which keep for a longer time the PAni particles suspended.

The shear stress versus shear rate data for all blends in the range of $0.01 \mathrm{t} 0100 \mathrm{~s}^{-1}$, were best fitted to the power-law model, Equation 2, this model are extensively used to describe the flow properties of non-Newtonian fluids ${ }^{[32,34]}$. As shown in Figure 1, all blend exhibited pseudoplastic behavior. The values for $n$, flow indexes, was between 0.41- 0.11, as shown in Table 2. Analyzing the addition of PAni in the acrylic paint it is observed a decreased in $n$ values as percentage of PAni increased. This result can indicate the interaction between Acrylic Paint and PAni which will produce a reduction on $n$ values, making the material with lower Newtonian characteristics, which is good for the technological paint applications. In the same way was noticed that the methodologies of dispersing influenced pseudoplastic characteristics.

On the other hand, the apparent viscosity at $100 \mathrm{~s}^{-1}(\mu \mathrm{a})$ increased as the PAni content increased, except for 5\%, as reported in Table 2. This behavior can indicate that when increase the shear rate, starting at $100 \mathrm{~s}^{-1}$, the PAni particles align rapidly in the direction of increasing shear rate and will produce less flow resistance. However, for $10 \%$ predominates the high amount of PAni in the paint which will elevate the viscosity values $^{[35]}$.

The consistency index $(\mathrm{K})$ indicates the degree of fluid resistance against the flow. The higher $\mathrm{K}$ values the material

Table 2. Parameters of power law models for Acrylic paint with PAni.

\begin{tabular}{|c|c|c|c|c|}
\hline PAni & $\begin{array}{c}\text { Apparent viscosity } \\
\text { at } 100 \mathrm{~s}^{-1} \text { (Pa.s) }\end{array}$ & $\begin{array}{c}\mathrm{K}^{\mathrm{a}} \\
\text { (Pa.s) }\end{array}$ & $\mathbf{n}^{\mathbf{b}}$ & $\mathbf{R}^{2 \mathrm{c}}$ \\
\hline 0 & 1.21 & 17.61 & 0.41 & 0.99 \\
\hline $5-\mathrm{M}$ & 0.91 & 53.34 & 0.11 & 0.97 \\
\hline $10-\mathrm{M}$ & 2.11 & 63.84 & 0.20 & 0.98 \\
\hline $5-U$ & 1.12 & 372.40 & 0.26 & 0.97 \\
\hline $10-\mathrm{U}$ & 2.86 & 1156.0 & 0.23 & 0.90 \\
\hline
\end{tabular}


is more consistent. The consistency index increase when the amount of PAni increase, $5 \%$ to $10 \% \mathrm{w} / \mathrm{w}$, in the same dispersion methodology. But the high changes in $\mathrm{K}$ values were observed when analyzing the dispersion methodology. Comparing PAni dispersion by mechanical mixer, was obtained $15 \%$ increase in $5 \%$ to $10 \% \mathrm{w} / \mathrm{w}$. But for $10 \%$ of PAni in acrylic paint by ultrasonic the $\mathrm{K}$ value increase around $1000 \%$ in relation of commercial acrylic paint.

\subsection{Creep and recovery}

A creep and recovery test is a two-part measurement which provides information about the paint, structural properties at very low stress. Figure $2 \mathrm{~A}$ shows a typical diagram of the output response from creep and recovery experiment that is the compliance $(\mathrm{J})$ as a function of time. The creep test is characterized by a constant stress is applied, which causes gradual deformation with time, through readjustment of the molecular structure of materials, dominated by the elastic component, followed by the viscoelastic component, where continuous flow occurs. The deformation of the materials is partially restored to its initial state, after unloading the stress on the materials. The more compliant is the molecular structure of sample, then the easier its space network deforms, when under the given shearing stress. The elastic creep compliance (JOC) is determined by linear extrapolation of the viscous regime of the creep curve while the elastic recoverable compliance (JOR) is the difference between the compliance at the end of the creep $\left(t=t_{2}\right)$ and recovery experiment $\left(t=t_{3}\right)$. The slope of the line of the viscous regime is also used to determine the zero shear viscosity $\left(\mu_{0}\right)$. Deformation of the paint was determined from absolute values of compliance and compared by the ratio $\left(\mathrm{J}_{3}-\mathrm{J}_{1}\right) / \mathrm{J}_{3}^{[36]}$.

In the recovery experiment, the extent of the recovery gives an indicating of the thixotropic regeneration of the paint. The extent of recovery R (\%) has previously been defined as ${ }^{[37]}$.

$$
R(\%)=\left(J O R / J_{3}\right) x 100
$$

A characteristic relaxation time $t_{r}$ may also yield a quantitative assessment of the thixotropic and may be determined as the product:

$$
t_{r}=\mu_{0} x J O C
$$

When a polymer is subjected to a constant load, it deforms continuously. The polymer will continue to deform slowly with time indefinitely or until rupture or yielding causes failure. This behavior will describe three regions, if the constant force continuum applied, the first region is the early stage of loading when the creep rate decreases rapidly with time. Then it reaches a steady region which is called the secondary creep stage followed by a rapid increase (tertiary region) and fracture. This phenomenon of deformation under load with time is called creep ${ }^{[34]}$.

The data values of the measured creep and recovery parameters for the acrylic paint are shown in Table 3 and, in Figure 2, the curves. The compliance during the creep test decreased significantly PAni presence. This suggests initially that the PAni really influence in acrylic paint on creep test and in the recovery, producing some interacting
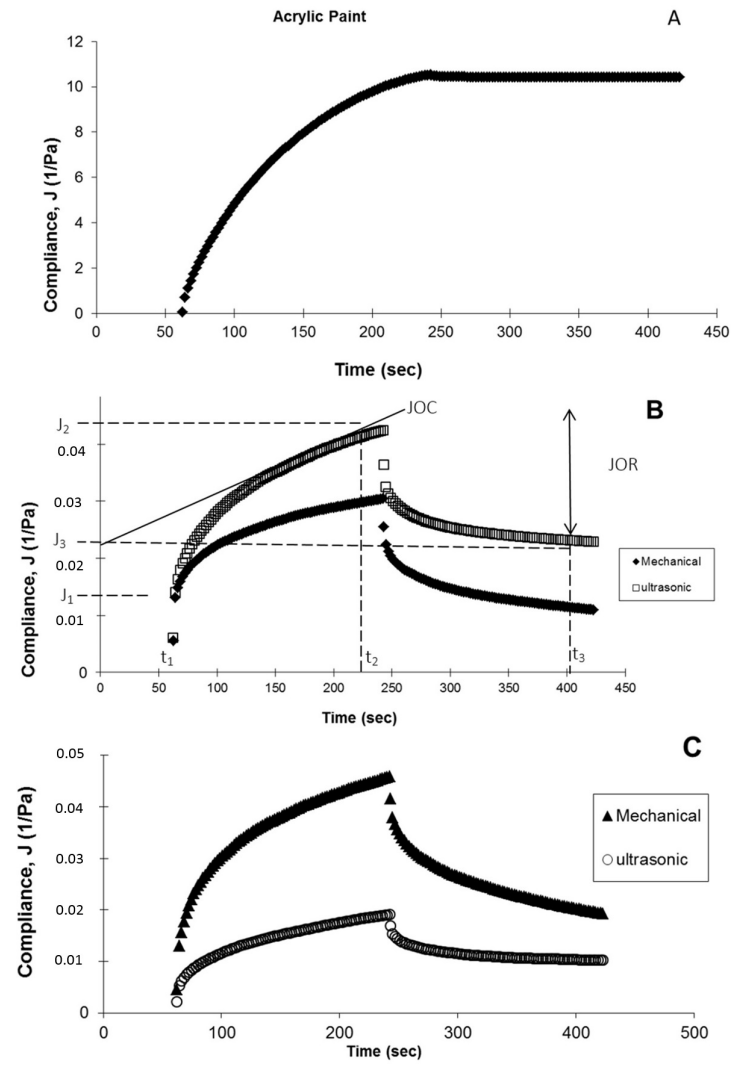

Figure 2. The Creep test (A) for Acrylic Paint; (B) for Pani 5\% and $(\mathrm{C})$ for $10 \%$ of PAni.

Table 3. Measured creep and recovery parameters for blends of acrylic paint and PAni.

\begin{tabular}{cccccc}
\hline \multicolumn{6}{c}{ Samples } \\
\hline & $\mathbf{0}$ & $\mathbf{5 - U}$ & $\mathbf{5 - M}$ & $\mathbf{1 0 - U}$ & $\mathbf{1 0 - M}$ \\
\hline$\mu_{0}$ (Pa.s) & 401 & $8.46 \times 10^{4}$ & $1.43 \times 10^{5}$ & $1.49 \times 10^{5}$ & $7.35 \times 10^{4}$ \\
$\mathrm{R} \%$ & 1.18 & 46.09 & 63.97 & 46.40 & 57.91 \\
$\mathrm{t}_{\mathrm{r}}(\mathrm{sec})$ & 664 & 539 & 690 & 393 & 493 \\
\hline
\end{tabular}

between the paint and polymer chain, because the blends are less readily deformable.

It is interesting to notice the changes in the curve of compliance versus time by the addition of 5 or $10 \% \mathrm{w} / \mathrm{w}$ of PAni. The curve with 5\% w/w of Pani in acrylic paint dispersed by mechanical mixer, Figure $2 \mathrm{~B}$, showed the lower values of compliance, which can indicate the bad homogenization of PAni in the paint. This suggestion of interpretation can be corroborated by the lower value of viscosity at $100 \mathrm{~s}^{-1}$, it will be easy alignment by the shear rate because the PAni particles are agglomerates. And when use a force to deform paint the agglomerates will act as a barrier. Probably the ultrasonic device deagglomeration not only PAni but others additives in paint that will reduce the resistance. When the amount of PAni increase to $10 \%$, the curve behavior change, the lower values of compliance were obtained to the ultrasonic dispersion, probably due the amount of deagglomeration and dispersion will be less, 


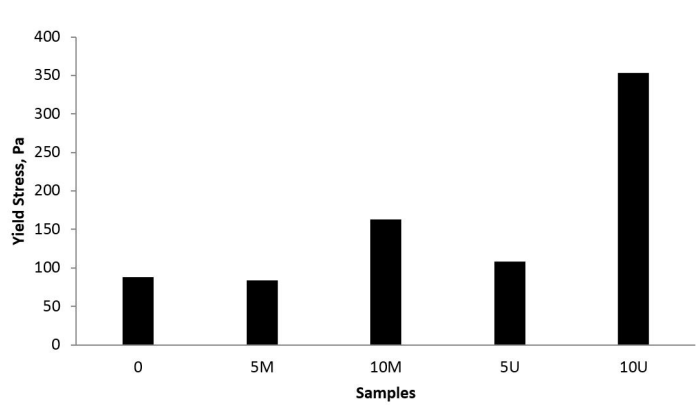

Figure 3. The Yield stress for conducting acrylic paint.

because there was more PAni in the blend. Generally, the filler increase leads to an increase in the total recovery and characteristic relaxation time of the paint. The recovery values $(\mathrm{R})$ were high to the samples with PAni. It can be attributed to the hydrogen bond that will help in the rebuild the acrylic paint structure. However, relaxation time, for the acrylic paint is similar to acrylic paint and acrylic paint with $5 \%$ of PAni. It is interesting noticed that the $10 \%$ of PAni reduce the value of relaxation time, probably due the reduction in the agglomeration. But the interpretation of all effect, like percent of deagglomeration, reducing in the PAni and acrylic resin molecular weight, influence of dispersion it is extremely difficult in a commercial paint. The zero shear viscosity is an indication that the energy to flow to paint and anti-settling. Zero shear viscosity values increased with increasing PAni content and changes were observed by the dispersion method. The behavior of zero shear viscosity was similar to being observed in compliance, high values to dispersion with $5 \%$ in mechanical mixer and $10 \%$ in the ultrasonic.

\subsection{Yield stress}

Yield stress $\left(\tau_{0}\right)$ is an important material property for the application of paint ${ }^{[38]}$. Yield stress measurements have previously been used to indicate the thixotropy of a material as a function of time ${ }^{[39-41]}$. The Yield stress values of acrylic paint modified with PAni are shown in Figure 3. It is not noticed variation on the yield stress for the addition of $5 \%$ of PAni in the acrylic paint. The addition of $10 \%$ was observed $50 \%$ increase in the yield stress for the mechanical dispersion methodology. But the high value in yield stress was observed when $10 \%$ of PAni is dispersed in acrylic paint by ultrasonic. This result can confirm the observation of the high energy dispersion of ultrasonic can reach not only in PAni but in all formulations components.

\section{Conclusions}

Results obtained in this paper showed that Polyaniline addition to acrylic paints, changes the rheological properties of the blends, due to the interactions established between acrylic and Polyaniline.

The creep and recovery tests showed changes in the curves by the addition of PAni and the methodology of dispersion. The paint blends had better recovery characteristic which is good for the paint application.
It was also observed an increase on thixotropy comparing to acrylic paint, except for composition $95 / 5 \mathrm{w} / \mathrm{w}$ mechanically dispersed, due to the observed decrease on both thixotropy and yield stress value, which indicates a lower interaction between the components from the mixtures, the best properties were obtained with $90 / 10 \mathrm{w} / \mathrm{w}$ dispersed by ultrasonic.

\section{Acknowledgements}

The authors express their sincere thanks to CNPq, CAPES and FAPERJ for financial support.

\section{References}

1. Heeger, A. J., Saricifti, N. S., \& Namdas, E. B. (2010). Semiconducting and metallic polymers (1st ed.). Oxford: Oxford University Press.

2. Bhadra, S., Khastgir, D., Singha, N. K., \& Lee, J. H. (2009). Progress in preparation, processing and applications of polyaniline. Progress in Polymer Science (Oxford), 34(8), 783810. http://dx.doi.org/10.1016/j.progpolymsci.2009.04.003.

3. MacDiarmid, A. G. (2001). Synthetic metals: a novel role for organic polymers (Nobel Lecture). Angewandte Chemie International Edition, 40(14), 2581-2590. http://dx.doi. org/10.1002/1521-3773(20010716)40:14<2581::AIDANIE2581>3.0.CO;2-2. PMid:11458347.

4. Jamadade, V. S., Dhawale, D. S., \& Lokhande, C. D. (2010) Studies on electrosynthesized leucoemeraldine, emeraldine and pernigraniline forms of polyaniline films and their supercapacitive behavior. Synthetic Metals, 160(9-10), 955960. http://dx.doi.org/10.1016/j.synthmet.2010.02.007.

5. Sathiyanarayanan, S., Muthukrishnan, S., \& Venkatachari, G. (2006). Performance of polyaniline pigmented vinyl acrylic coating on steel in aqueous solutions. Progress in Organic Coatings, 55(1), 5-10. http://dx.doi.org/10.1016/j. porgcoat.2005.09.002.

6. Sathiyanarayanan, S., Muthukrishnan, S., Venkatachari, G., \& Trivedi, D. C. (2005). Corrosion protection of steel by polyaniline pigmented paint. Progress in Organic Coatings, 53(4), 297-301. http://dx.doi.org/10.1016/j.porgcoat.2005.03.007.

7. Seegmiller, J. C., Silva, J. E. P., Buttry, D. A., Torresi, S. I. C., \& Torresi, R. M. (2005). Mechanism of action of corrosion protection coating for AA2024-T3 based on Poly(aniline)Poly(methymethacrylate) blend corrosion, passivation and anodic films. Journal of the Electrochemical Society, 152, 45-53. http://dx.doi.org/10.1149/1.1839472.

8. Epstein, A. J., Smallfield, J. A., Guan, O. H., \& Fahlman, M. (1999). Corrosion protection of aluminum and aluminum alloys by polyanilines: A potentiodynamic and photoelectron spectroscopy study. Synthetic Metals, 102(1-3), 1374-1376. http://dx.doi.org/10.1016/S0379-6779(98)00383-X.

9. Kinlen, P. J., Menon, V., \& Ding, Y. (1999). Mechanistic investigation of polyaniline corrosion protection using the scanning reference electrodo technique. Journal of the Electrochemical Society, 146(10), 3690-3695. http://dx.doi. org/10.1149/1.1392535.

10. Shacklette, L. W., Miller, G. G., Elesenbaumer, R. L., Han, C., Webling, B. M., \& Wessling, B. (1994). US Patent No 52.81363. Washington: U.S. Patent and Trademark Office.

11. Dhawan, S. K., Singh, N., \& Venkatachalam, S. (2002). Shielding behavior of conducting polyaniline composites. Synthetic Metals, 129, 261-267. http://dx.doi.org/10.1016/ S0379-6779(02)00079-6.

12. Zhu, J., Chen, M., Qu, H., Zhang, X., Wei, H., Luo, Z., Colorado, H. A., Wei, S., \& Guo, Z. (2012). Interfacial 
polymerized polyaniline/graphite oxide nanocomposites toward electrochemical energy storage. Polymer, 53(25), 5953-5964. http://dx.doi.org/10.1016/j.polymer.2012.10.002.

13. Yilmaz, H., Zengin, H., \& Unal, H. I. (2012). Synthesis and electrorheological properties of polyaniline/silicon dioxide composites. Journal of Materials Science, 47(13), 5276-5286. http://dx.doi.org/10.1007/s10853-012-6413-3.

14. Kumar, S., Singh, V., Aggarwal, S., \& Mandal, U. K. (2009). Synthesis of 1-dimensional polyaniline nanofibers by reverse microemulsion. Colloid \& Polymer Science, 287(9), 1107-1110. http://dx.doi.org/10.1007/s00396-009-2078-0.

15. Amaral, T. P., Barra, G. M. O., Barcia, F. L., \& Soares, B. G. (2001). Polyaniline/Epoxy Resin Conducting Blend. Polímeros. Ciência e Tecnologia, 11, 149-157. http://dx.doi.org/10.1590/ S0104-14282001000300015.

16. Valentová, H., \& Stejskal, J. (2010). Mechanical properties of polyaniline. Synthetic Metals, 160(7-8), 832-834. http:// dx.doi.org/10.1016/j.synthmet.2010.01.007.

17. Bhattacharya, A., \& De, A. (1999). Conducting polymers in solution: progress toward processibility. Journal of Macromolecular Science Review. Macromolecular Chemistry and Physics, C39(1), 17-56. http://dx.doi.org/10.1081/MC100101416.

18. Zhai, D., Liu, B., Shi, Y., Pan, L., Yaqun, W., Wenbo, L., Rong, Z., \& Guihua, Y. (2013). Highly Sensitive Glucose Sensor Based on Pt Nanoparticle/Polyaniline Hydrogel Heterostructures. ACS Nano, 7(4), 3540-3546. http://dx.doi.org/10.1021/nn400482d. PMid:23472636.

19. Barra, G. M. O., Matins, R. R., Kafer, K. A., Paniago, R., Vasques, C. T., \& Pires, A. T. N. (2008). Thermoplastic elastomer/polyaniline blends: evaluation of mechanical and electromechanical properties. Polymer Testing, 27(7), 886-892. http://dx.doi.org/10.1016/j.polymertesting.2008.07.004.

20. Oueiny, C., Berlioz, S., \& Perrin, F. X. (2014). Carbon nanotube: polyaniline composites. Progress in Polymer Science, 39(4), 707-748. http://dx.doi.org/10.1016/j.progpolymsci.2013.08.009.

21. Sudha, J. D., Sivakala, S., Prasanth, R., Reena, V. L., \& Nair, P. R. (2009). Development of electromagnetic shielding materials from the conductive blends of polyaniline and polyaniline-clay nanocomposite EVA: Preparation and properties. Composites Science and Technology, 69(3-4), 358-364. http://dx.doi. org/10.1016/j.compscitech.2008.10.026.

22. Oyharçabal, M., Olingaa, T., Foulca, M. P., \& Vigneras, V. (2012). Polyaniline/clay as nanostructured conductive filler for electrically conductive epoxy composites. Influence of filler morphology, chemical nature of reagents, and curing conditions on composite conductivity. Synthetic Metals, 162 (78), 555-562. http://dx.doi.org/10.1016/j.synthmet.2012.02.011.

23. Navarchian, A. H., Joulazadeh, M., \& Karimi, F. (2014). Investigation of corrosion protection performance of epoxy coatings modified by polyaniline/clay nanocomposites on steel surfaces. Progress in Organic Coatings, 77(2), 347-353. http://dx.doi.org/10.1016/j.porgcoat.2013.10.008.

24. Dhibar, S., Sahoo, S., Das, C. K., \& Singh, R. (2013). Investigations on copper chloride doped polyaniline composites as efficient electrode materials for supercapacitor applications. Journal of Materials Science, 24, 576-585. http://dx.doi.org/10.1007/ s10854-012-0800-z.

25. Garai, A., \& Nandi, A. (2008). Rheology of (6)-camphor10 -sulfonic acid doped polyaniline-m-cresol conducting gel nanocomposites. Journal of Polymer Science. Part B, Polymer Physics, 46(1), 28-40. http://dx.doi.org/10.1002/polb.21339.

26. Gangopadhyay, R. (2008). Exploring rheological properties of aqueous polyaniline-PVP dispersion. Journal of Polymer
Science. Part B, Polymer Physics, 46(22), 2443-2455. http:// dx.doi.org/10.1002/polb.21574.

27. Gangopadhyay, R. (2009). Exploring properties of PolyanilineSDS dispersion: a rheological approach. Journal of Colloid and Interface Science, 338(2), 435-443. http://dx.doi.org/10.1016/j. jcis.2009.06.050. PMid:19665141.

28. Schoff, C. K. (2005). Organic coatings: the paradoxical materials. Progress in Organic Coatings, 1(1), 21-27. http:// dx.doi.org/10.1016/j.porgcoat.2004.05.001.

29. Plesu, N., Hiescu, S., Ilia, G., Popa, A., \& Muntean, C. (2006). Rheology of polyaniline in acrylic resin. Turkish Journal of Chemistry, 30, 155-163. Retrieved in 17 April 2015, from http://journals.tubitak.gov.tr/chem/issues/kim-06-30-2/kim30-2-4-0505-11.pdf

30. Soares, B. G., Leyva, M. E., Barra, G. M. O., \& Khastgir, D. (2006). Dielectric behavior of polyaniline synthesized by different techniques. European Polymer Journal, 42(3), 676686. http://dx.doi.org/10.1016/j.eurpolymj.2005.08.013.

31. Möginger, B. (1993). The determination of a general time creep compliance relation of linear viscoelastic materials under constant load and its extension to nonlinear viscoelastic behavior for the burger model. Rheologica Acta, 32, 370-379. http://dx.doi.org/10.1007/BF00435083.

32. Roussel, N. (2006). A thixotropy model for fresh fluid concretes: Theory, validation and applications. Cement and Concrete Research, 36(10), 1797-1806. http://dx.doi.org/10.1016/j. cemconres.2006.05.025

33. Posdorfer, J., \& Wessling, B. (2001). Oxidation of copper in the presence of the organic metal polyaniline. Synthetic Metals, 119(1-3), 363-364. http://dx.doi.org/10.1016/S03796779(00)01393-X.

34. Barnes, H. A., Hutton, J. F., \& Walters, K. (1989). An introduction to rheology. New York: Elsevier Applied Science.

35. Chacko, A. P., Hardaker, S. S., Gregory, R. V., \& Samuels, R. J. (1997). Viscoelastic characterization of concentrated polyaniline solutions: new insights into conductive polymer processing. Synthetic Metals, 84(1-3), 41-45. http://dx.doi. org/10.1016/S0379-6779(97)80660-1.

36. Nguty, E., \& Ekere, N. N. (2000). The rheological properties of solder and solar pastes and the effect on stencil printing. Rheologica Acta, 39(6), 607-612. http://dx.doi.org/10.1007/ s003970000117.

37. Diez-Sales, O., Hernández, M. J., Casanova, A., \& Herraez, M. (2007). Rheological characterization of chitosan matrices: influence of biopolymer concentration. Journal of Applied Polymer Science, 105(4), 2121-2128. http://dx.doi.org/10.1002/ app. 25577.

38. Fraioli, A. V. (1974). Yield values in thick-film rheology. Solid State Technology, 17, 48-50.

39. Krestser, R. G., \& Boger, D. V. (2001). A structure model for time-dependent recovery of mineral suspension. Rheologica Acta, 40(6), 582-590. http://dx.doi.org/10.1007/s003970100180.

40. Coussot, P. Tabuteau, H., \& Ovarlez, G. (2006). Aging as solid or liquid behavior in pastes. Journal of Rheology, 50, 975-994. http://dx.doi.org/10.1122/1.2337259

41. Sirqueira, A. S., Cardozo, Z. N., \& Pinto, P. R. (2014). Rheology of acrylic paint. Acta Scientiae et Thecnicae, 2, 7-9. Retrieved in 17 April 2015, from http://www.uezo.rj.gov.br/ojs/index. php/ast/article/view/60

Received: Apr. 17, 2015

Revised: Oct. 21, 2015

Accepted: Feb. 15, 2016 